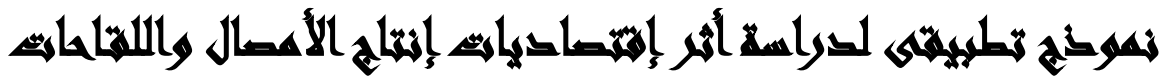

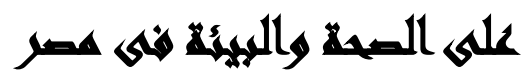

[10]

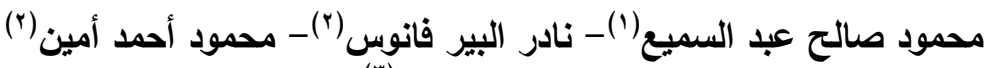

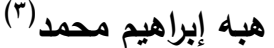

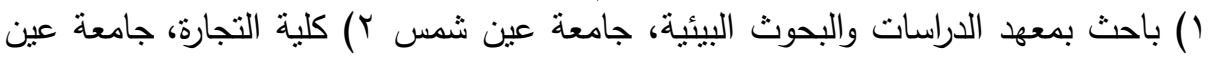
شمس ץ) الثركة المصرية لخدمات نقل الدم الثرات

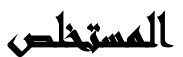

هدفت هذه الدراسة الى إعداد نموذج تطبيقى لدراسة أثز اقتصاديات إنتاج الأمصال

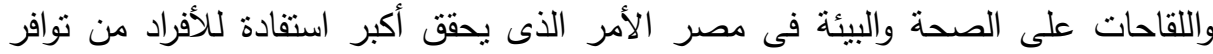
الأمصال واللقاحات وسهولة عملية التحصين والتى توفر الحماية للأفراد، وبهذا فإن التهات مشكلة

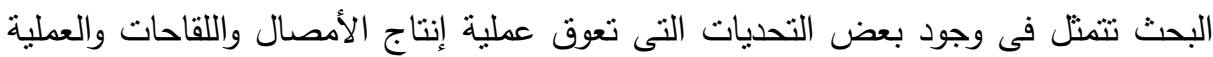

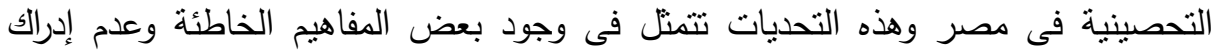

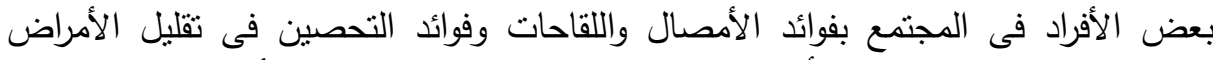

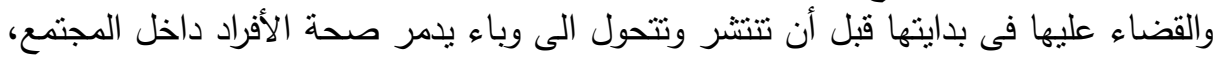

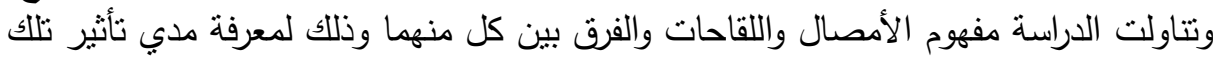
التحديات على إنتاج الأمصال واللقاحات والعملية التحصينية، ومدي تأثنير العملية التحصينية

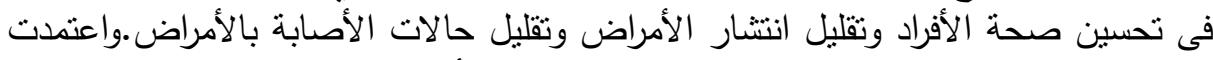

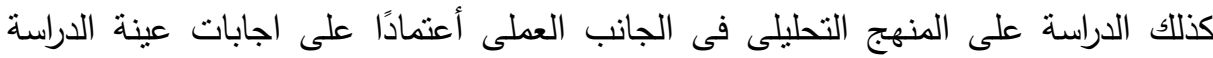

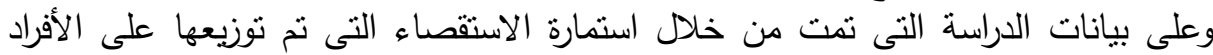

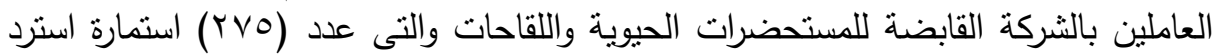

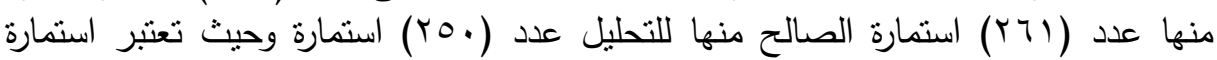

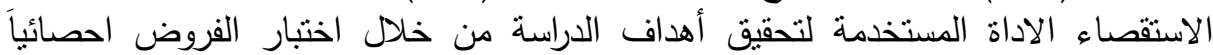

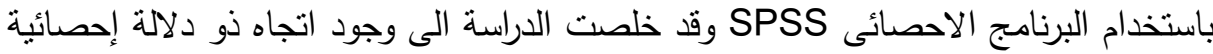

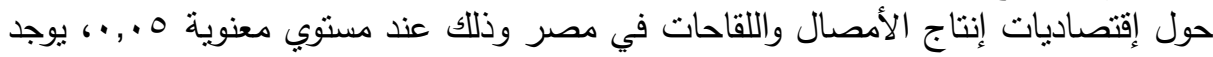

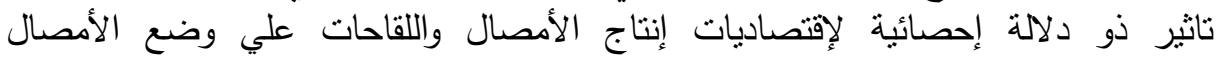

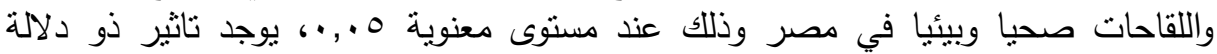

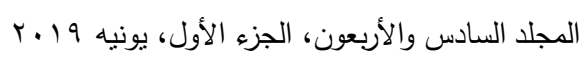


إحصائية لإقتصاديات إنتاج الأمصال واللقاحات علي وضع الأمصال واللقاحات صحيا وبيئيا في مصر وذلك عند مستوى معنوية 0 .,

\section{$x$}

تعتبر صحة الافراد والمجتمعات هى حالة اكتمال السلامة البدنية والعقلية والاجتماعية وليس مجرد غياب او انعدام المرض او العجز، او هى الحالة المنوازنة للكائن الحى والتى لهى

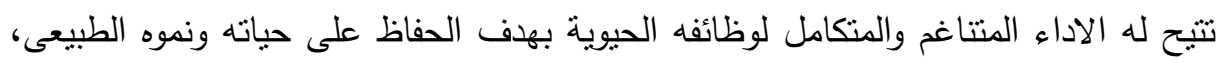
وللمحافظة على صحة الانسان يجب اتباع اساليب ونظم دقيقة فى استخدام الادوية والأمصال واللقاحات بطريقة اكثر امنا واقل نكلفة، ويعتبر علم الأمصال (Serology) هو علم يبحث

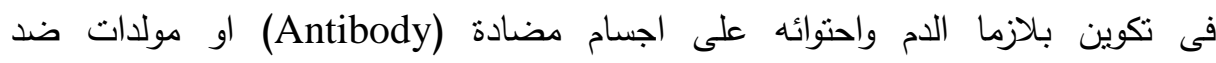

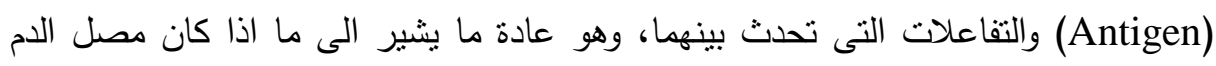

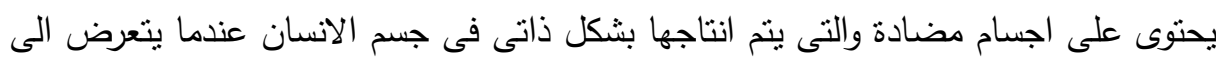

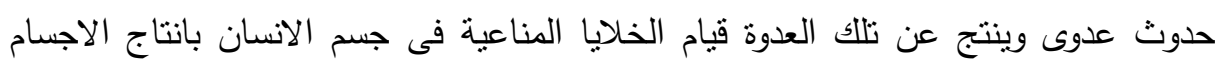
المضادة لتقوم بعملية الدفاع عن الجسم ضد مسببات العدوى. وتعتبر عملية استخدام اللقاحات من اهم التدخلات التى ساهمت فى تحسين وضع الصحة العامة فى المجتمع وذلك من خلاد

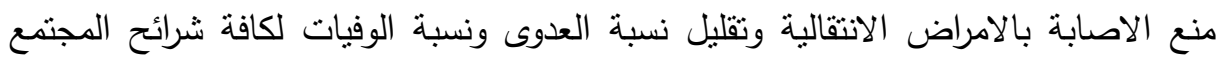

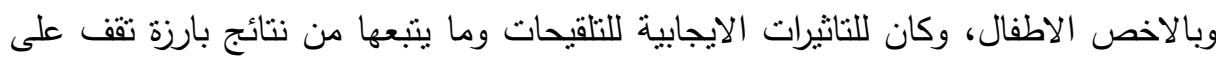
نفس المستوى مع تدخلين مهمين وهما توفير ماء امن وصالح للشرب، وكذللك استخدام المضادات الحيوية فى مقاومة الجراثيم، ويعد التحصين من الوسائل التى تهدف الى توفير

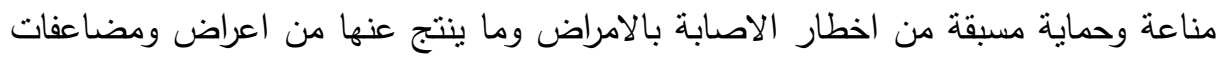
قد تؤدى الى الوفاة، اما اللقاح فهى مادة تعطى للانسان بهدف تحفيز الجهاز المناعى لعملية

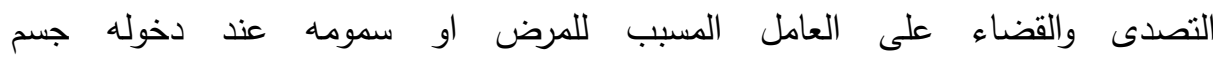

$$
\text { الانسان (القحطانى، • ( • ( ) ). }
$$

ويعتبر المحافظة على صحة الفرد والمجتمع من الهدف الرئيس والتى ينت من خلالها

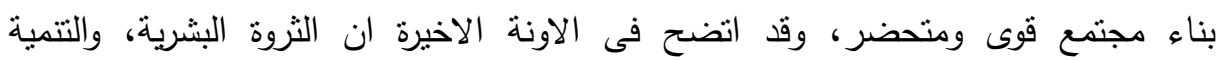

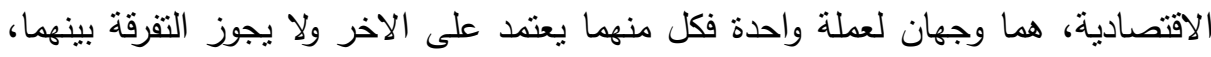

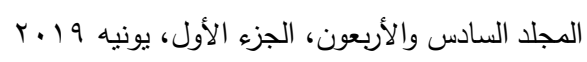


ويعتقد بعض الاشخاص ان حماية البيئة، والتتمية الاقتصادية هدفان متعارضان وان هناك

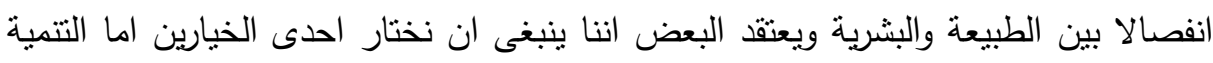

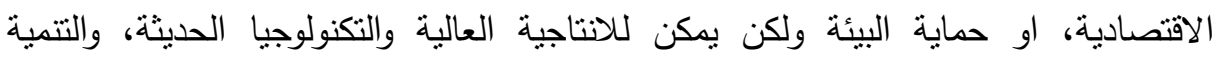
الاقتصادية، ان تتفق مع بيئة صحية، بل يجب ان يتم النوافق بينهما ،والا تعذر استمرار عملية التمية . أصبح الناس مؤخرا على قدر كبير من الدراية بقضايا البيئة، كذلك أصبحو يشعرون بالصلة بين عمليات الانتاج وانماط الاستهلاك وبين التكاليف الصحية التى تضر البيئة وقد

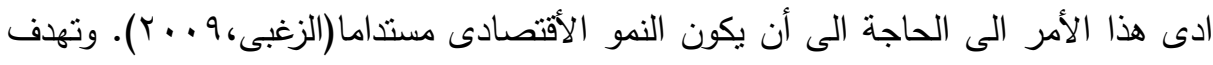

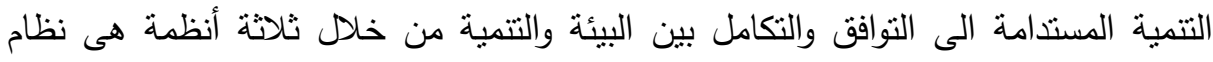

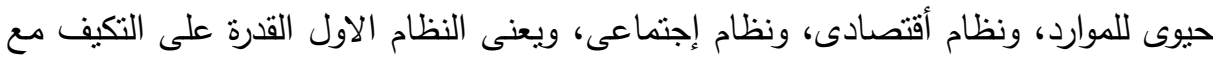

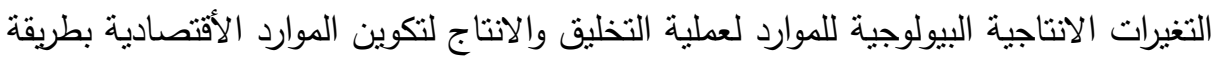

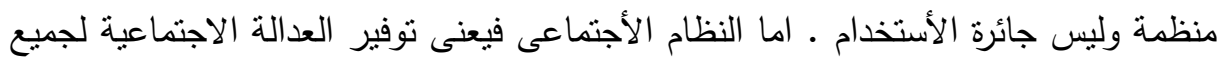
فئات المجتمع، وأخيرآ النظام الأقتصادى وهو يعنى القدرة على تحقيق حالة التوازن بين الاستهلاك والانتاج لتحقيق التمية المنشودة التى تهدف الى التحسين المستمر فى نوعية

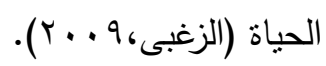

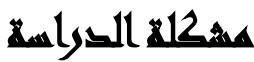

رغم التقدم الموجود فى مجال الصحة العالمية ألا أن ما يقرب من ثلث سكان العالم

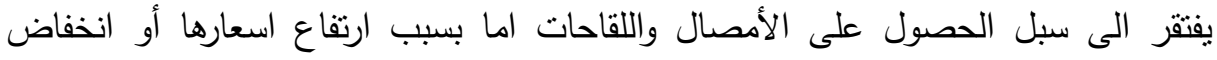

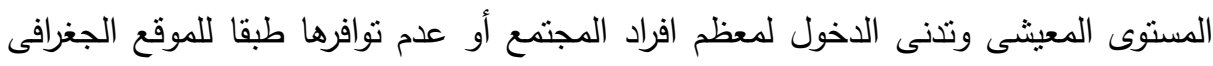

الذى يتعزر معه وصول هذه الأمصال والطعوم الى بعض المناطق الريفية النائية . ويواجه العالم اليوم مشكلة اساسية حيث شهدت السنوات الاخيرة زيادة سريعة فى التطور التكنولوجى حول العالم مما يعنى زيادة قدرة الافراد على معرفة أسباب المشكلات وكيفية التغلب عليها بشكل اسرع مما كان عليه الوضع قبل سابق، وبخلاف ذللك فقد تدهورت بالفعل

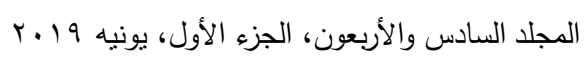


الحالة الصحية لكثير من الافراد فى المجتمعات النامية وذللك لتدنى نسبة دخول الآفراد وعدم

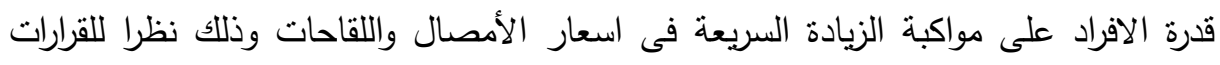

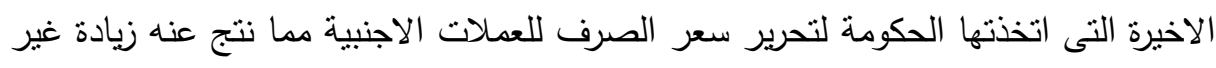

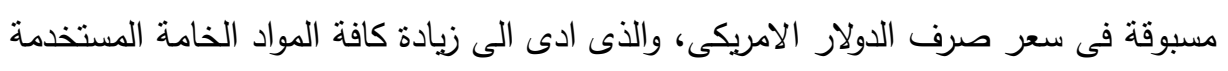

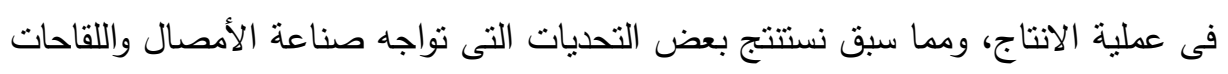
وهى:

1-تدنى النظم الصحية المقدمة للمواطنين

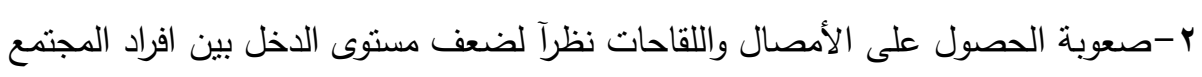

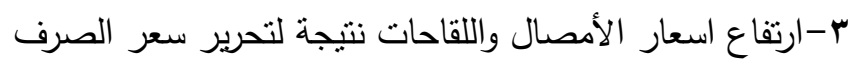

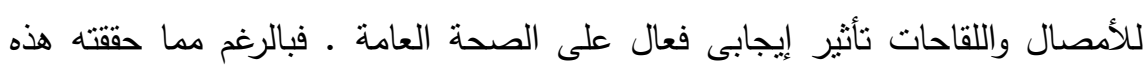

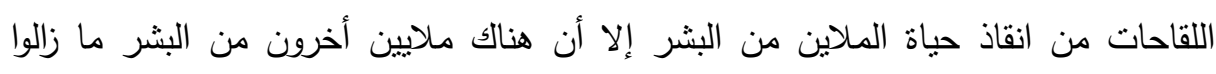

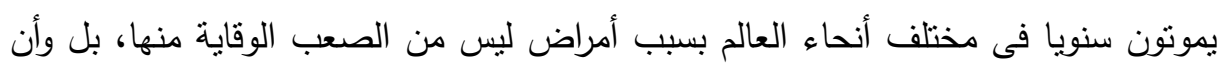

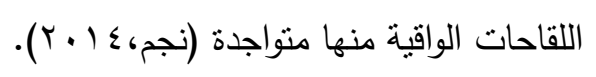

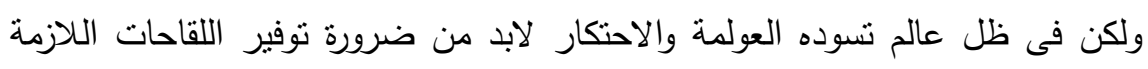

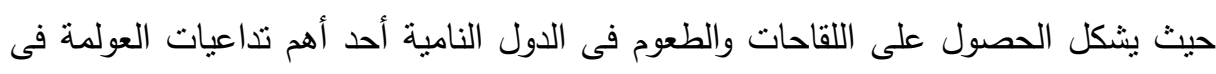

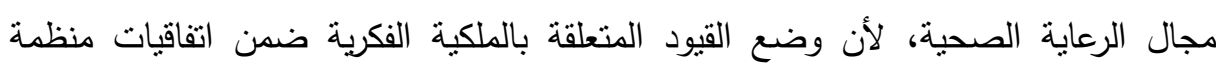

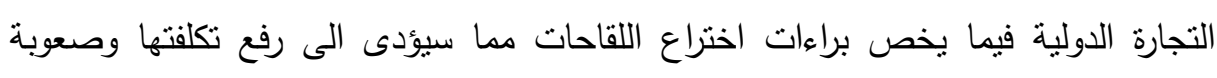
الحصول عليها ومع التغيرات التى طرأت على الصعيد العالمى والتحديات التى نواجه

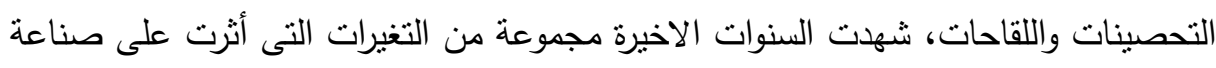

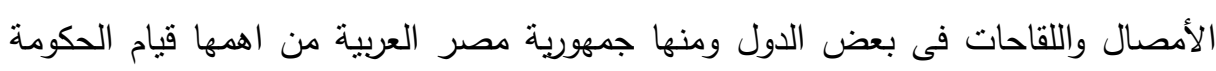
بالاتجاه نحو عملية الخصخصة باعتبارها خطوة نحو تحقيق التتمية الاقتصادية وتقليل الضغط على ميزانية الحكومة ومن بين المنشات الحكومية فى الدول النامية التى تم تحويلها وهى الهيئة العامة للمستحضرات الحيوية واللقاحات وقد نم صدور قرار بتحويلها الى (الثركة القابضة للمستحضرات الحيوية واللقاحات ) والتى تتبع قطاع الاعمال العام وتواجه الدولة

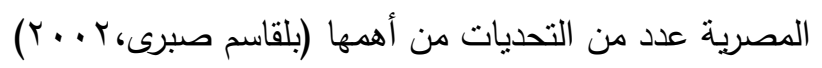


- عدم قيام الحكومة بدعم شركات قطاع ألاعمال وذلك لعدم تحميل موازنة الدولة بأعباء

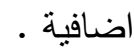
- انخفاض رؤوس الاموال المستتمرة فى مجال انتاج الأمصال واللقاحات. - ارتفاع تكاليف التكنولوجيا المستوردة بعد تطبيق حماية حقوق الملكية الفكرية وحظر تقليد

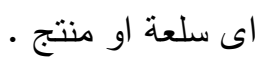
- ارتفاع اسعار استيراد المواد الخام الخاصة بالاتتاج وذلك بسبب تحرير سعر الصرف (نجم، (r)

ومع ارتفاع معدلات التلوث البيئى التى باتت تهدد صحة الإنسان بصورة عامة، وفى إنى المنطقة العربية بصفة أساسية وفى مصر بصفة خاصة لآنتشار الصناعات كثيفة الاعتماد

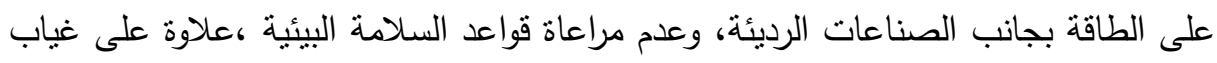

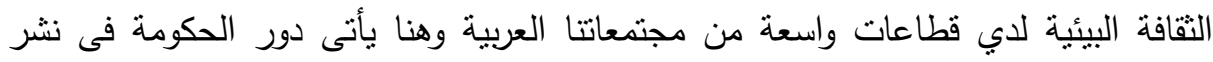

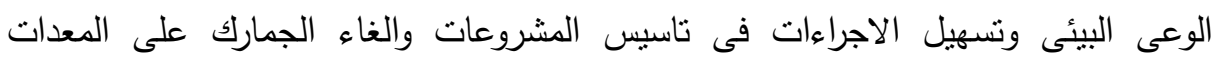

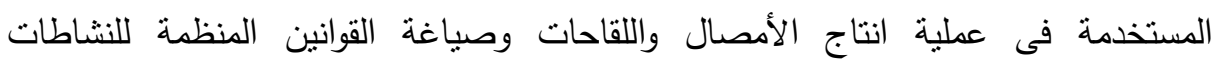
الاقتصادية فى مجال تصنيع الأمصال واللقاحات والادوية و من جانب الخر يجب والب مشاركة

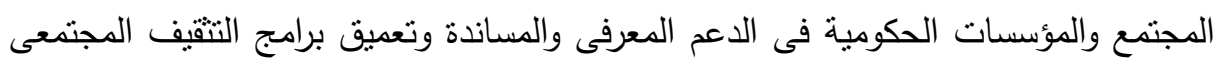
حول برامج وحملات التطعيمات التى تقوم بها وزارة الصحة لتساعد على الحد من انتشار

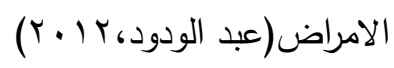

وعلى الرغم من نجاح الأمصال واللقاحات فى الوقاية من الامراض ومكافحتها فانها لا لإنال تزل لايها القدرة على المساهمة على نطاق أوسع من ذللك فى تحسين الحالة الصحية للافراد

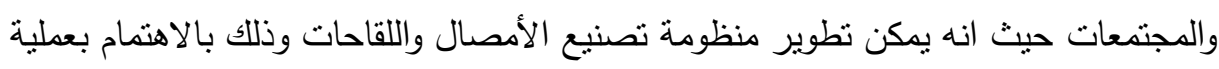
البحث العلمى فى مجال تصنيع اللقاحات والاستفادة من الخبرات العالمية من بعض الدف الدول

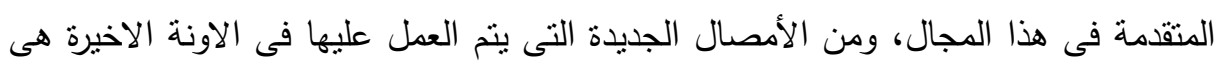

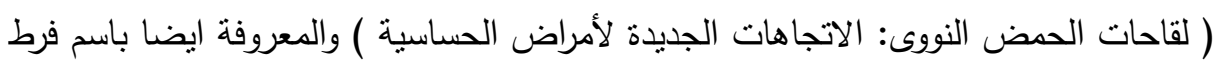


الحساسية وهو ان الجهاز المناعى حساس لبعض البروتينات الاجنبية التى عادة ما تكون غير

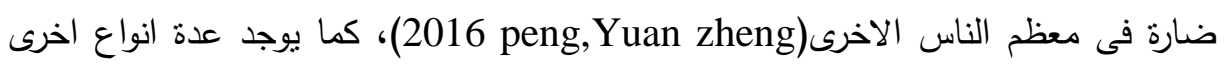

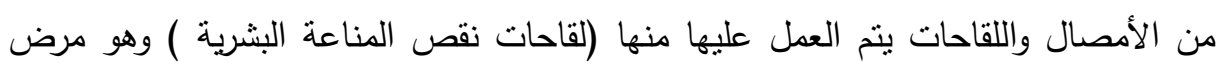

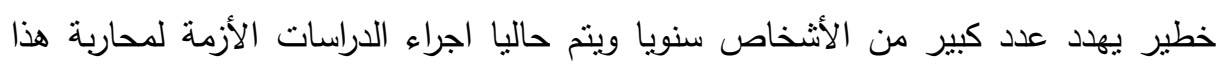
الفيروس الخطير (2016) Bahar Ramezanpour). وكذلك لقاح (الأنفلـونزا ) وكيفة يمكن تطويره للمحافظة على صحة الافراد(2016BaharRamezanpour).

وسوف تتتاول الدراسة اقتصاديات انتاج الأمصال واللقاحات فى مصر منمنلة فى في الثركة القابضة للمستحضرات الحيوية واللقاحات وهل يمكن توفير امصال وطعوم باسعار التار

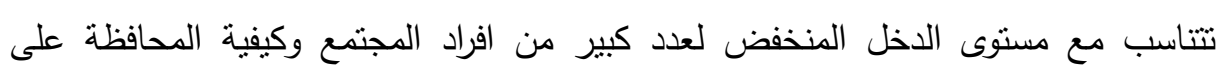

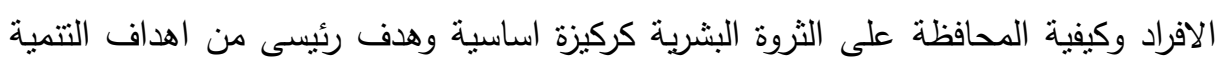

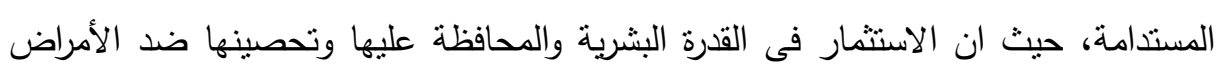

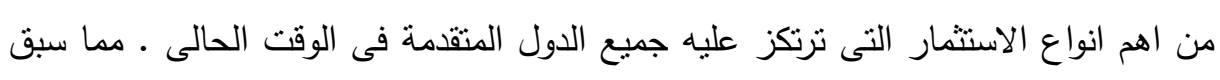

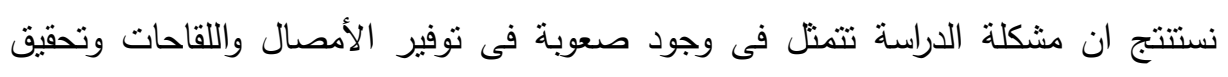

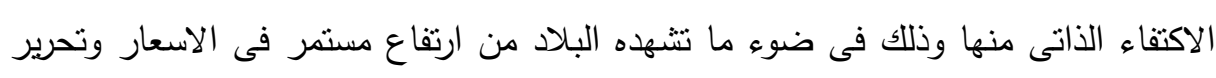
سعر الصرف الصفاء

\section{أسئل التوراسمة}

تسعى الدراسة الى الأجابة على سوال جوهرى وهو :

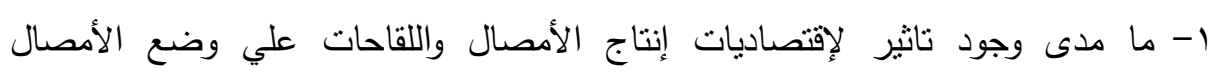

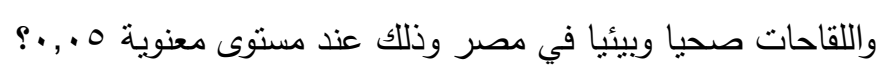

ويستمد منه عدة اسئلة فرعية ومنها:

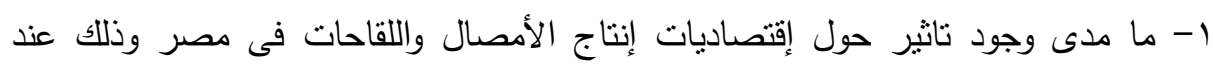

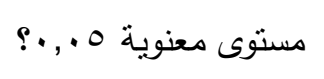

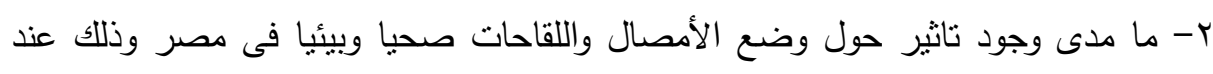

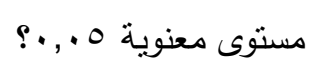




\section{أهساهيت التراهة}

يهدف البحث إلى تحقيق عدة أهداف ومنها:

1-التعرف على تاثير إقتصاديات إنتاج الأمصال واللقاحات علي وضع الأمصال واللقاحات صحيا وبيئيا في مصر وذلك عند مستوى معنوية ه .,

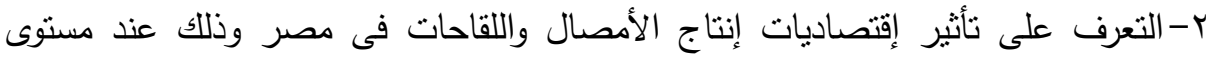
معنوية 0. r-التعرف على تأثثير وضع الأمصال واللقاحات على الصحة والبيئة فى مصر • وذلك عند

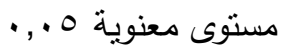

\section{هزوضه التراسمة}

1-لا يوجد تاثير ذو دلالة إحصائية لإقتصاديات إنتاج الأمصال واللقاحات علي وضع

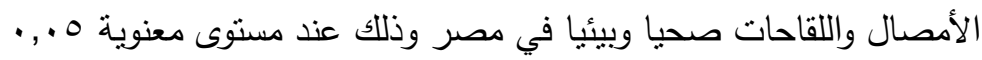

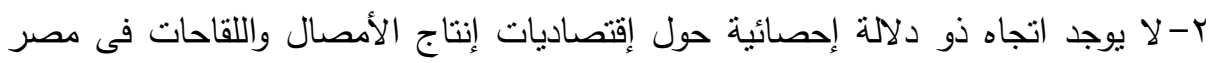
وذللك عند مستوي معنوية 0 ., ץ-لا يوجد اتجاه ذو دلالة إحصائية حول وضع الأمصال واللقاحات فى مصر وذلك منك عند

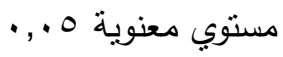

\section{aصو}

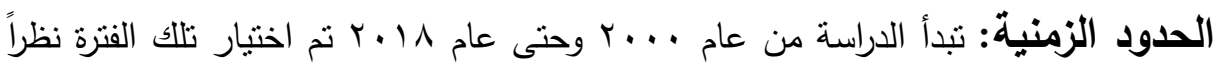
لتوافر قد كبير من البيانات عن الأمصال واللقاحات عن تلك الفترة الحدود المكانية: يتم التطبيق على جمهورية مصر العربية متمنلة فى (الشركة القابضة للمستحضرات الحيوية واللقاحات Vacsera) 


\section{منهمج السواسها}

تعتمد الدراسة على المنهج الإستقرائى الذى يعتمد على الأسلوب الوصفى والأسلوب

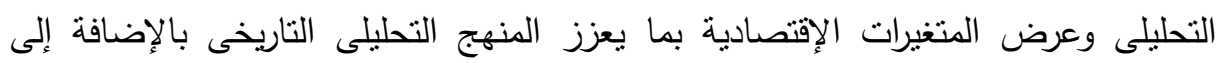

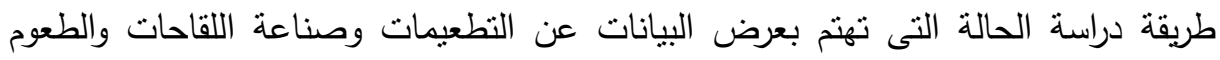
وتحديد المشكلة قيد البحث، ومن ثم تحليل وتفسير البيانات للوصول إلى وضع توصيات

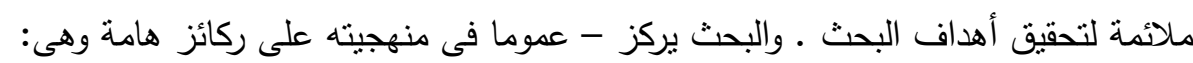
دراسة استقرائية: يتم من خلال تجميع البيانات والمعلومات اللازمة فى عملية البحث وتحليل وذلك بالاستعانة بمجموعة من المراجع العربية والأجنبية .

دراسة ميدانية: يتم ذلك عن طريق التوجه الى وزارة الصحة، والثركة القابضة للمستحضرات الحيوية واللقاحات والثركات التابعة، وكذلك الإستعانة بالبيانات الإحصائية

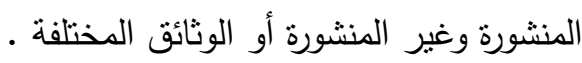

\section{أهمي التصواسم}

ترجع أهمية الدراسة الى دراسة اقتصاديات انتاج الأمصال واللقاحات وأثزها على الصحة

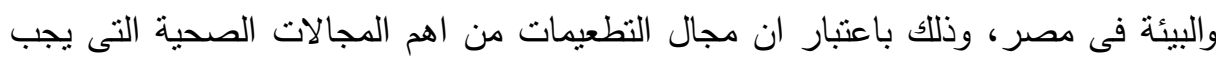

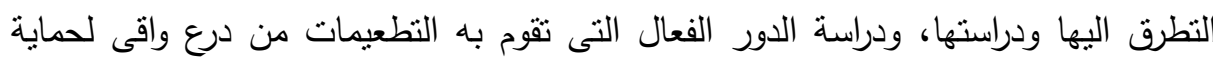

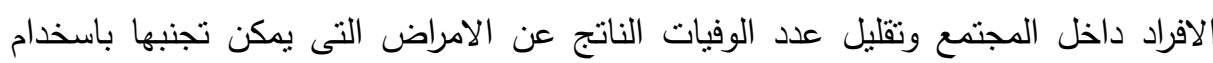

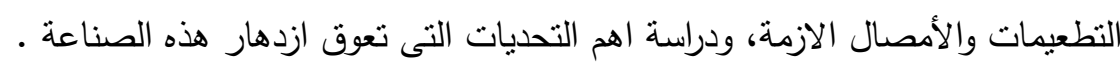

\section{همسلحاهي التراسلة}

1-الأمصال: تعرف الأمصال بأنها عبارة عن الأجسام المضادة الجاهزة التى نم تحضيرها وتجهيزها معمليًا، أو هى مضادات سموم جاهزة التحضبير، والتى تؤدى مفعولها فور

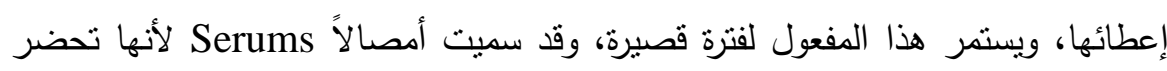
من مصل عائل آخر، ثم بعد ذللك يتم نقلها عن طريق الحقن العضلى أو الوريدى(رباب

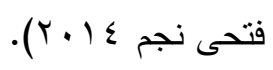

$$
\text { المجلد السادس والأربعون، الجزء الأول، يونيه } 19
$$


r-اللقاحات: هى منتجات بيولوجية biological products تقوم بعمل تحسين المناعة

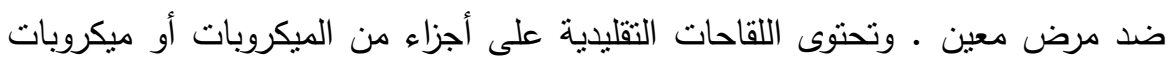

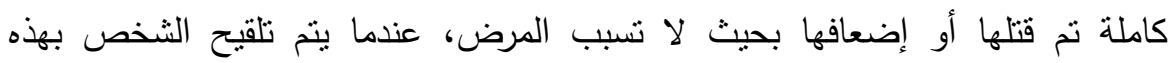

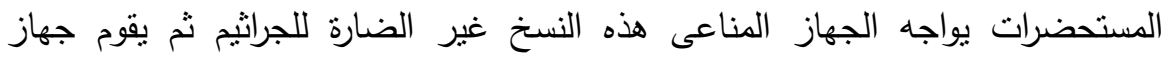
المناعة بإزالتها بسرعة من جسم الإنسان فى المقابل ـ ينذكر الجسم الجراثيم بحيث فى وقت لاحق فى الحياة عندما يصادف الجراثيم الخبيثة الحية الحقيقية قد يكون جهاز المناعة قادر على محاربة ثلك الجراثيم بناء على الذاكرة المحتجزة ضد جرثومة

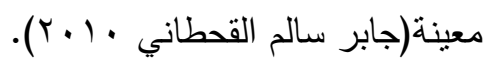

ب-البيئة: تعرف البيئة بانها الوسط أو المجال الكائن الذى يعيش فيه الإنسان بما يضمه من

$$
\text { ضواهر طبيعية وبشرية يتأثر بها ويؤير فيها (شوقى السيد ب. . . ب). }
$$

تعرف البيئة أيضا بأنها المحيط الذى يشمل كل الأثياء الحية وغير الحية والتفاعلات بينها ونتائج هذه التفاعلات على اختلاف أوضاعها، ولها مفهوماً لا متتاهياً نتيجة هذه

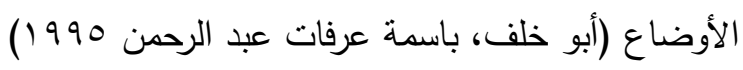

ع-الصحة: الصحة هي الحالة المنوازنة للكائن الحي والتي تتتح له الأداء المتتاغم والمتكامل لوظائفه الحيوية بهدف الحفاظ على حياته ونموه الطبيعي(منظمة الصحة

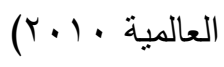

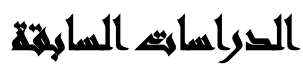

1-دراسة نجم ، ع 1 ـ ب " نموذج اقتصادى قياسى مقترح لقياس أثر التغطية التحصينية باللقاحات فى تخفيض معدل وفيات الأطفال (حديثى الولادة والرضع والاقل من خمس

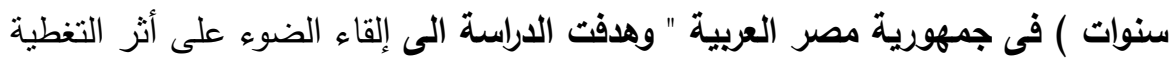

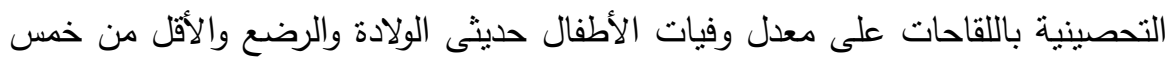

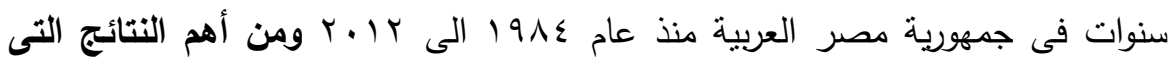


توصلت اليها الدراسة أن المتغيرات المستقلة فى النماذج الثلاثة تفسر وتترح التغيرات فى

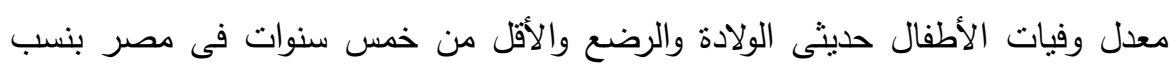

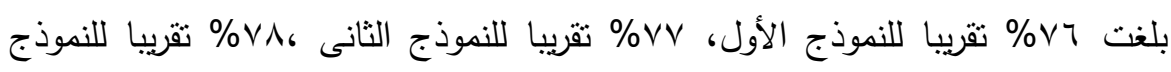

r-دراسة نجم ، ؛ 1 • r "العولمة ودورها فى توافر اللقاحات والأمصال واتاحتها للاول النامية "وهدفت الاراسة الى اختبار صحة أو خطا الفروض التى قامت عليها، من خلا وله تعريف اللقاحات والأمصال وأنواعها، ودراسة دور العولمة فى التأثير على التى اللقاحات واتاحتها فى فى الدول النامية من خلال دراسة أهم الاثار الإيجابية والسلبية لاتفاقية

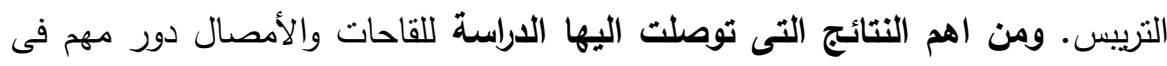
الوقاية من الأمراض منذ القدم، حيث ساعدت فى القضاء على مرض الجدرى وشلل

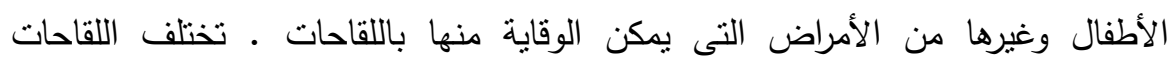
والطعوم عن الأدوية باعتبارها منتجات بيولوجية (كائنات حية دقيق) وليست منتجات كيمائية (كالأدوية ) تتطلب جودة وفاعلية أكثر تعقيدا وتكلفة حيث أن عملية إنتاج اللقاح تعتمد على "المعرفة الفنية. للعولمة انعكاسات سلبية فى توفير اللقاحات والأمصال لشعوبه

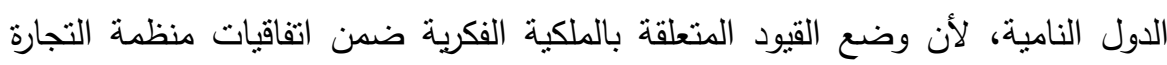

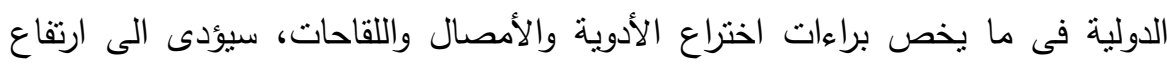
تكلفتها وصعوبة إناحتها فى الدول النامية الفقيرة .

r-دراسة عبد الودود، Y 1 ب : " الاقتصاد الأخضر :تثمية مستدامة تراعى الصحة والبيئة" وهدفت الاراسة الى زيادة الوعى لدى الأفراد وزيادة الوعى البيئى لديهم وكيفية

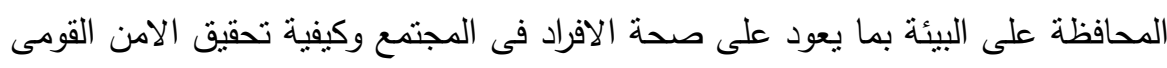

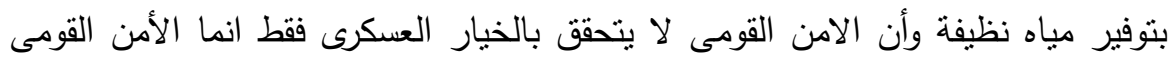

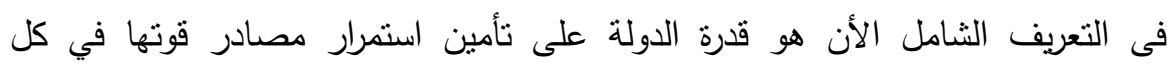

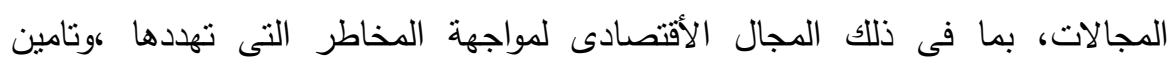

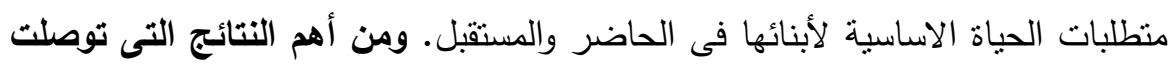
اليها الدراسة يجب زيادة وتعميق برامج التثقيف المجتمعى حول الأنثطة النظيفة بيئيا. 
قيام الحكومة بمساندة مشروعات الاقتصاد الأخضر عبر تسهيل الاجراءات فى تأسيس منل نلك المشروعات، والغاء الجمارك عن مستلزمات هذه الصناعة .

ع - دراسة ( Bahar, Ramezanpour 2016 (

Cross-Sect oral Perspectives of Market Implementation of the MVA Platform for Influenza Vaccines: Regulatory, Industry and Academia

هدفت الدراسة التى توضيح ومعرفة النطورات الحديثة والنهج الجديد فى مجال لقاح الأنفونزا

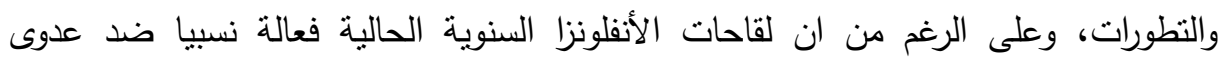

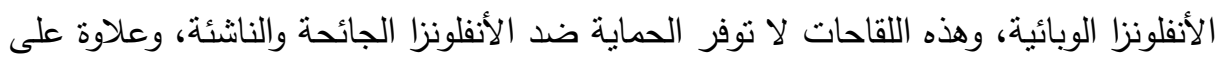

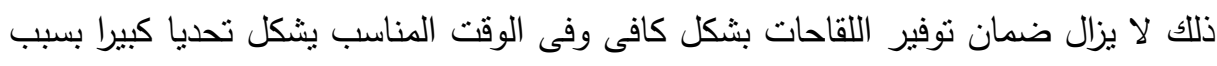

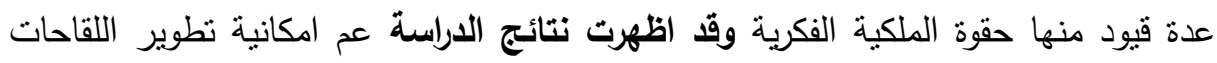

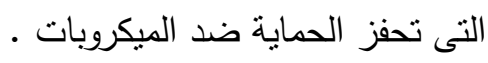

0 - دراسة (Venkateswarlu,Chamcha 2016)

\section{Current Scenario and Future Prospects of HIV Vaccines}

تهاف الدراسة التى توضيح ومعرفة دور اللقاحات التى يمكن من خلالها السيطرة على فيروس

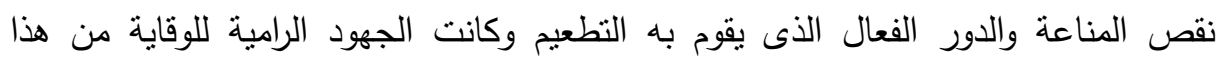
فيروس نقص المناعة البشرية متفائلة لأن هذه الجهود قامت بخفض به العدوى الجديدة التى

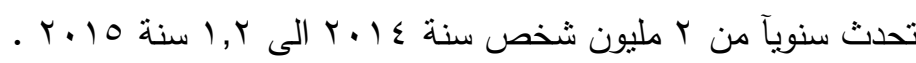

צeng,YuanZheng2016)

DNA Vaccines: The New Directions to Allergic Diseases

تهدف الدراسة الى اكتثاف لقاح جديد يساعد على تقليل العناء على مرضى الحساسية وتقوم

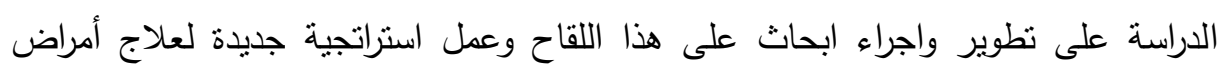

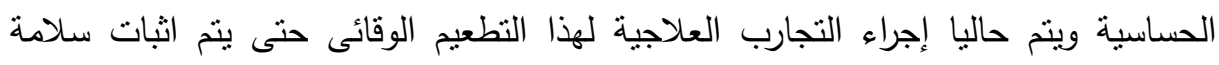
التطعيم علاجات لمنع عمل وسطاء التحسس وإزالة الخلايا منل مضادات الهيستامين 
والسكريات القشرية وإيينيفرينيتكا، طريقة أخرى أكثر فائدة لبعض أنواع الحساسية التي يمكن أن تؤدي إلى تغيير المسار الطبيعي لأمراض الحساسية.

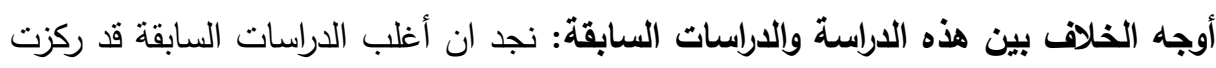

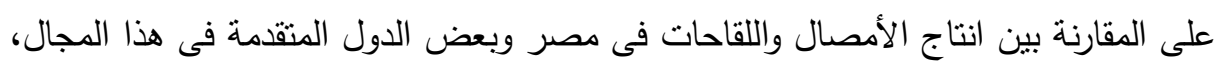

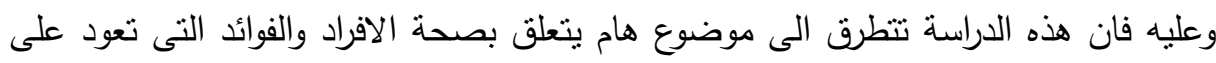

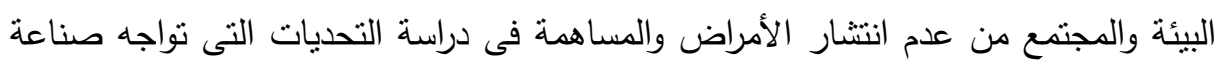
الأمصال واللقاحات فى مصر ومدى أمكانية نوفير أمصال وللقاحات ذات جودة عالية وتكلفة

\section{أجراعاهي التراسمة}

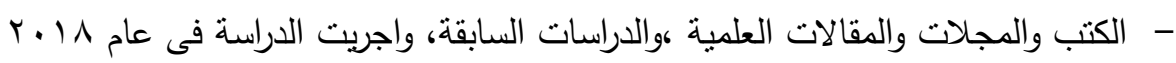

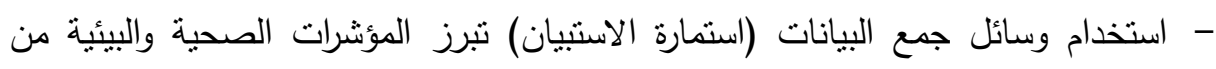
اقتصاديات انتاج الامصال واللقاحات التى تركز عليها هذه الدراسة.

- تحليل البيانات وتقيمها والتركيز على نقاط القوة والضعف للاستفادة منها.

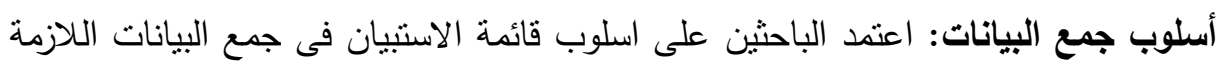
لاختبار فروض الدراسة حيث قام الباحثين بإعداد قائمة استبيان تتضمن:

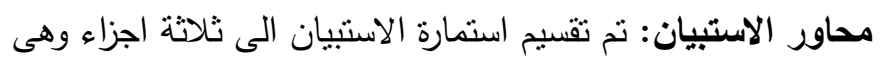

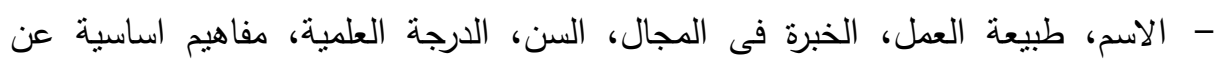
الدراسة - المحور الاول: يناقش هذا المحور إقتصاديات إنتاج الأمصال واللقاحات فى مصر

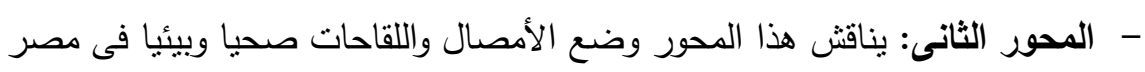
مجتمع الاراسة: يشمل مجتمع الدراسة التطبيق على الثركة القابضة للمستحضرات الحيوية

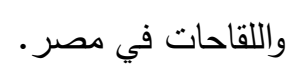
عينة الدراسة: اشتملت عينة الدراسة وعلى الثركة القابضة للمستحضرات الحيوية تمت الدراسة من خلال استمارة الاستقصاء التى نم توزيعها على الأفراد العاملين بالثركة القابضة وعله

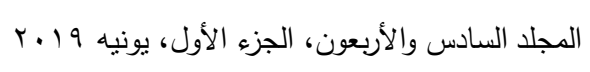


للمستحضرات الحيوية واللقاحات عددها (YV0) استمارة استرد منها عدد (rآY) استمارة

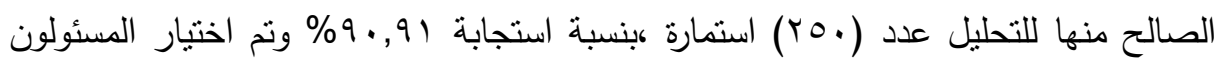

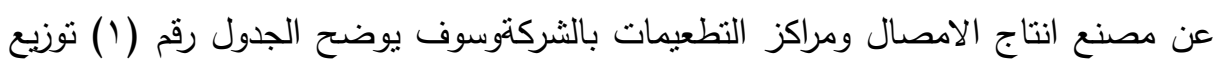
عينة الدراسة جدول توزيع عينة الدراسة

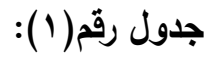

\begin{tabular}{|c|c|c|c|}
\hline نسبة الاستجابة & عدد القوائم الصالحة للتحليل & عدد القوائم المستلمة & عدد القوائم المسلمة \\
\hline$\% 90.91$ & 250 & 261 & 275 \\
\hline
\end{tabular}

أسلوب التحليل الإحصائي: نم استخدام بعض المفاهيم الإحصائية في هذه الدراسة كما يلي: - الأهمية النسبية: تم حساب الأهية النسبية لكل عبارة من عبارات أبعاد الدراسة وذلك

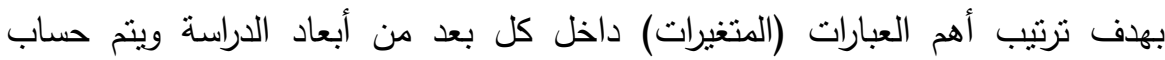
الأهمية النسبية من خلال العلاقة الآتية:

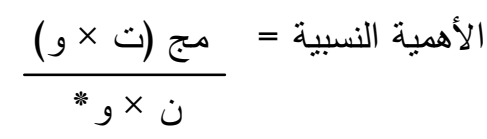

حيث ت = التكرار المقابل لكل استجابة و = الدرجة المقابلة لكل استجابة

و = أكبر درجة استجابة (0) ن = إجمالي عينة الدراسة

r- اختبار الاشارة: اختبار الاشارة هو اختبار فروض لا معلمي، يتم باستخدام إحصاءة

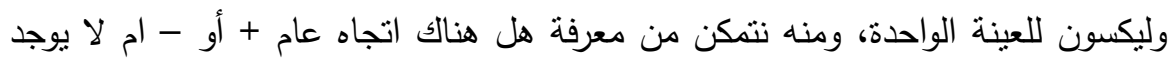

$$
\text { اتجاه معين (محايدة) داخل مجتمع. }
$$

r- مقياس ليكرت الخماسي: نستخدم بصفة عامة مقايس ليكرت لمعرفة الاتجاه العام لأراء المستجبين للإجابة على اسئلة الرفض و القبول المتدرجة (المعروفة بسلم ليكرت) و في ليكي

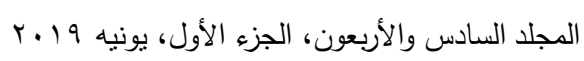


البداية كان يستخدم المقياس الثائي (موافق أوغير موافق) ثم ظهر المقياس ثنائي القطب (سلم ليكارت) فتطور من مقياس ليكرت الثلاثي (موافق - محايد - غير موافق ) ليصل الرباعي و الخماسي حتي وصل لمقياس ليكرت التسيعي.

ع - الموثوقيه ومعامل الصدق: تستخدم الموثوقية لإجراء إختبار الثبات لأسئلة الاسنبيان المستخدمة في جمع البيانات باستخدام إحد معاملات الثبات مثل ألفا كرونباخ، و تتراوح قيم الفا كرونباخ بين الصفر و الواحد و كلما إرتفعت قيم معامل الثبات و أقتربت من فن إندان

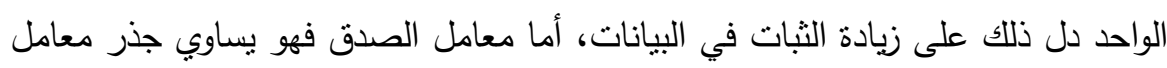

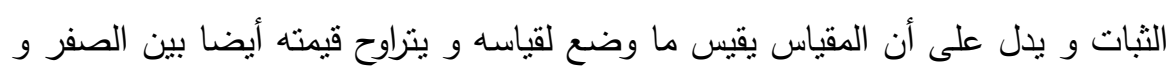

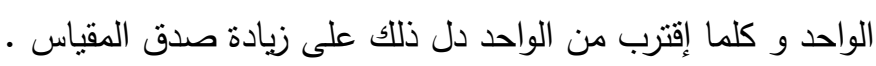

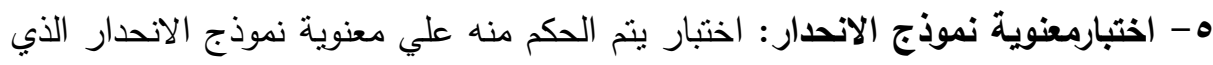

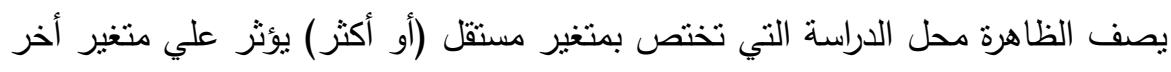

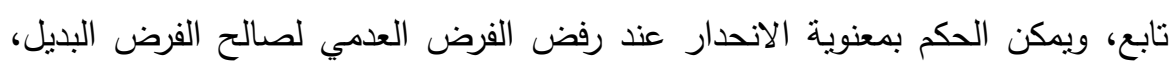
والفرض العدمي يفترض دائما ان نموذج الانحدار غير الانير معنوي.

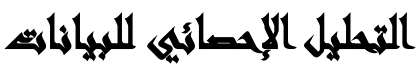

بعد ترميز وتفريغ البيانات وإدخالها للحاسب الآلي، تم استخدام البرنامج الإحصائي في إجراء التحليل الإحصائي لبيانات الدراسة النطبيقية على النحو التالي:

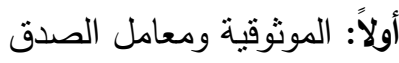
ثانيا: التوزيع التكراري والأهمية النسبية و إتجاه مقياس ليكرت الهنوف الخماسي

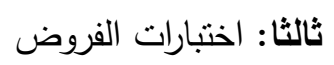

ويتناول الباحثين كل عنصر من العناصر السابقة بشيء من التفصيل كما يلي:

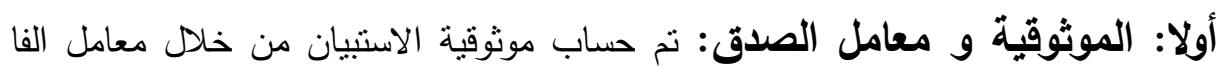

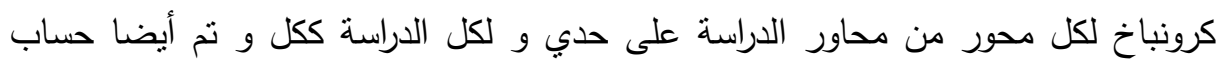
معامل الصدق كما هو موضح بالجدول الاتي: مرن مرون 


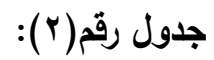

\begin{tabular}{|c|c|c|c|}
\hline معامل الصدق الذاتى & معامل الفا كرونباخ & عدد المفردات & المحور \\
\hline 0.985 & 0.972 & 9 & الاول \\
\hline 0.991 & 0.984 & 9 & الثاني \\
\hline 0.994 & 0.989 & 18 & الدراسة ككل \\
\hline
\end{tabular}

المصدر: من أعداد الباحثين من مخرجات برنامج SPSS

ومن الجدول السابق يتضح ان قيم معاملات الفا كرونباخ مرتفعة مما يعكس مدي ثنات بنات

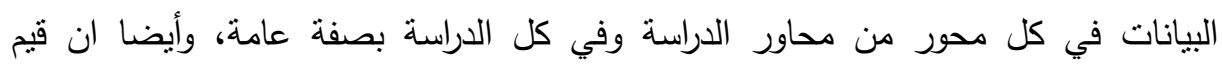
معاملات صدق المفردات مرتفعة مما يعكس مصداقية المقياس.

ويمكننا استخدام مقياس أخر للصدق يسمي بصدق الاتساق عن طريق حسكاب حسب معاملات الارتباط بين الدرجة الكلية للمقياس وكل بعد من ابعاد المقياس باستخدام معامل ارتباط سبيرمان(وذلك نظرا لعدم خضوع المحاور الفرعية للتوزيع الطبيعي ).

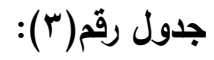

\begin{tabular}{|c|c|c|c|}
\hline القيمة الاحتمالية & معامل الارتباط مع الارجة الكلية للمقياس & الابعاد & 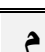 \\
\hline$\overline{c, \ldots}$ & $* 0.998$ & المحور الاول & 1 \\
\hline$\cdot, \cdots$ & $* 0.982$ & المحور الثانى & $r$ \\
\hline
\end{tabular}
* دال عند مستوى (0. ., ) المصدر: من أعداد الباحثين من مخرجات برنامج (ه)

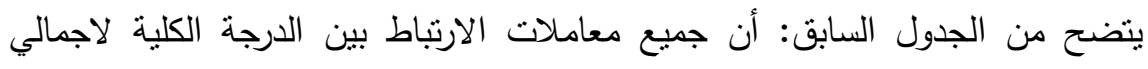

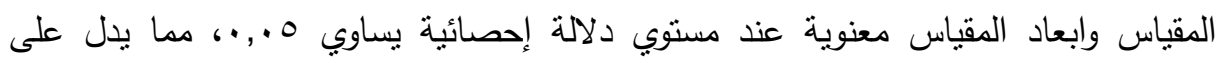
صدق جميع ابعاد المقياس.

\section{ثانيا: التوزيع التكراري والأهمية النسبية:}

المحور الاول: يحتوي المحور الاول على 9 عبارات حول إقتصاديات إنتاج الأمصال

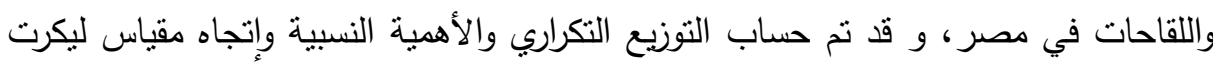

$$
\text { لكل عبارة على حدي. }
$$


جدول رقم(؛ ):

\begin{tabular}{|c|c|c|c|c|}
\hline ل اتيكرت & المعياري & المتوسط & الأهمية النسبية & العبارة \\
\hline موافق & 1.24 & 3.82 & 76.32 & اسعار الأمصال واللقاحات في مصر . فى رفع \\
\hline 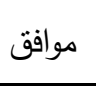 & 1.11 & 4.02 & 80.32 & بعض ب-تسبب تحرير سعر الصرات في المراكز في قلّة توافر. \\
\hline موافق & 0.81 & 4.19 & 83.76 & التحصينية في مصرير سعر الصرف على العملية \\
\hline موافق & 1.14 & 4.18 & 83.68 & 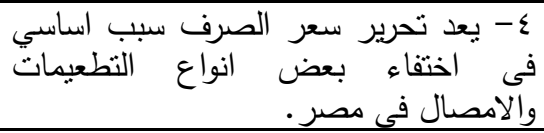 \\
\hline موافق & 0.58 & 4.19 & 83.84 & الرئيسية التى نوراجه العملية التحصينية من في التحديات \\
\hline جدافق & 1.08 & 4.26 & 85.28 & استطاعة بعضب تحرير الاشتراص الصرفى فى الحصول \\
\hline موافق & 0.87 & 3.7 & 74.08 & 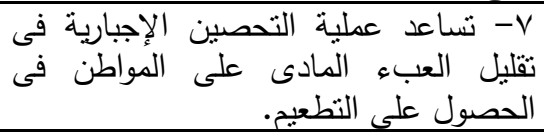 \\
\hline جدافق & 0.77 & 4.66 & 93.28 & 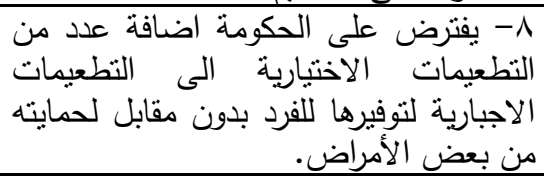 \\
\hline موافق & 0.85 & 3.74 & 74.72 & 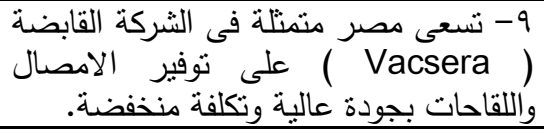 \\
\hline موافق & & & الاول & المتوسط المرجح لإجمالي \\
\hline
\end{tabular}

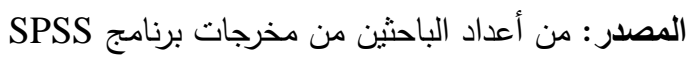

ويتضح من الجدول السابق ان اتجاه اراء عينة الدراسة هو الموافقة على إقتصاديات إنتاج

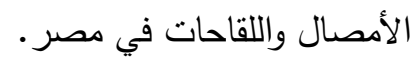

المحور الثاني: يحتوي المحور الاول على 9 عبارات حول وضع الأمصال واللقاحات صحيا

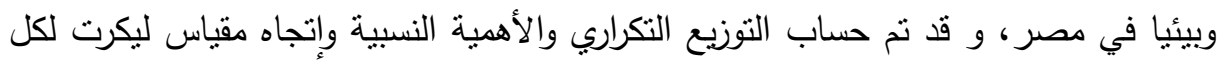

عبارة على حدي 
مجلة العلوم البيئية

معهد الدراسات والبحوث البيئية - جامعة عين شمس لهـ لهن

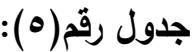

\begin{tabular}{|c|c|c|c|c|}
\hline ل اليكرت & المعياري & المتوسط & $\begin{array}{c}\text { الاهمية النسبية } \\
\%\end{array}$ & 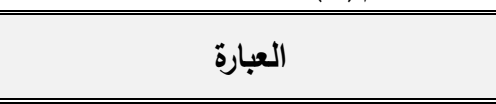 \\
\hline 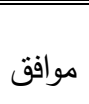 & 1.12 & 3.76 & 75.12 & التحديات التى نواجه العملية التحصينية المدية \\
\hline 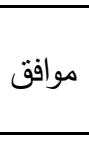 & 0.92 & 3.96 & 79.2 & 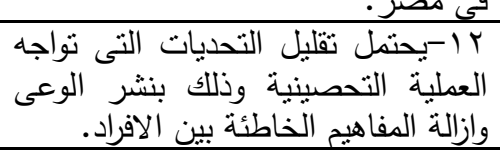 \\
\hline 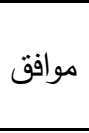 & 1.08 & 3.84 & 76.88 & 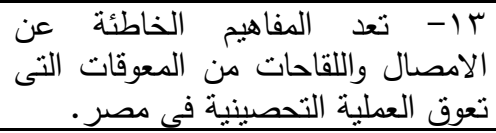 \\
\hline موافق & 1.08 & 4.26 & 85.28 & على إنتشار عملية التحصيني. بين الوعين الافراد \\
\hline موافق & 0.89 & 3.76 & 75.28 & 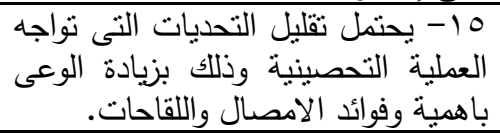 \\
\hline موافق & 1.06 & 4.46 & 89.2 & إنتشار الأمراض عملية الافصراد. 17 التصن فى تقليق \\
\hline 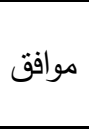 & 1.19 & 3.43 & 68.56 & 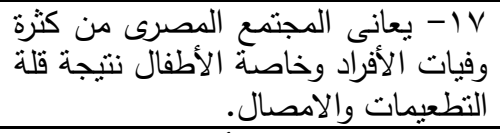 \\
\hline موافق & 1.19 & 4.38 & 87.6 & عدد حملات النظعيمات الإجبارية. \\
\hline موافق & 1.03 & 3.9 & 77.92 & 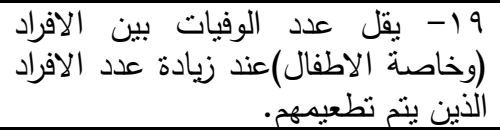 \\
\hline موافق & \multicolumn{4}{|c|}{ المتوسط المرجح لإجمالى المحور الثانى هو ب,qV } \\
\hline
\end{tabular}

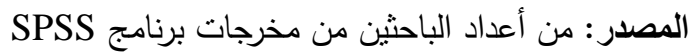

ويتضح من الجدول السابق ان اتجاه اراء عينة الدراسة هو الموافقة على وضع الأمصال

واللقاحات صحيا وبيئيا في مصر . 


\section{ثالثا: اختبارات الفروض:}

أ- إختبارات جودة التوفيق: من إجل اختبار أن عبارات الاستبيان تخضع للتوزيع الطبيعي، تم

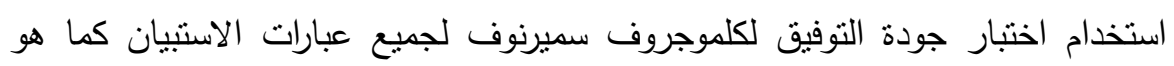

$$
\text { موضح في الجدول التالي: }
$$

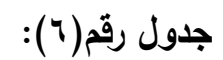

\begin{tabular}{|c|c|c|c|}
\hline نتيجة الاختبار & P-Value & أحصاءة كلموجروف سميرنوف & العبارة \\
\hline غير معنوي & $\cdot, \cdots$ & $* \cdot, Y Y I$ & المحور الاول \\
\hline غير معنوي & $\cdot, \cdots$ & $*, r \vee 0$ & المحور الثاني \\
\hline غير معنوي & $\cdot, \cdots$ & $*, Y M r$ & إجمالى الاستنيان \\
\hline
\end{tabular}

المصدر: من أعداد الباحثين من مخرجات برنامج SPSS

ويتضح من الجدول السابق: انه نستطيع رفض الفرضي العدمي، لصالح الفرض البدين البديل القائل

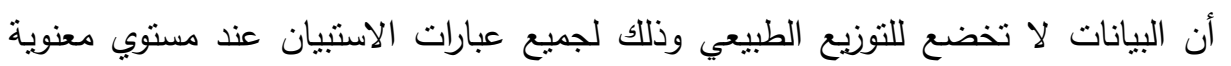

ب- اختبار الاشارة: في ظل عدم خضوع العبارات والمحاور الرئيسية للتوزيع الطبيعي (كما

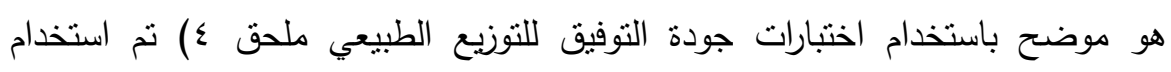
الاحصاء اللامعلمي وبالتحديد اختبار الاشارة لبحث الفروض التالية:

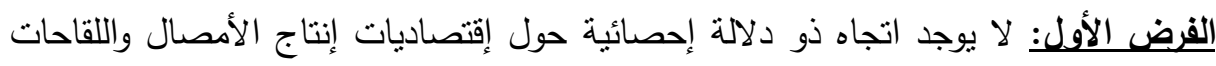
في مصر وذلك عند مستوي معنوية 0 ., .

الفرض الثاني: لا يوجد اتجاه ذو دلالة إحصائية حول وضع الأمصال واللقاحات صحيا وبئي هبئيا

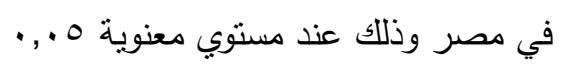


أولا: الفرض الأول: نتائج اختبارات الفروض للمحور الاول :

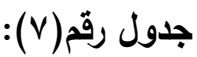

\begin{tabular}{|c|c|c|c|}
\hline 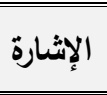 & الاتجاه & $\begin{array}{c}\mathbf{P}- \\
\text { value }\end{array}$ & 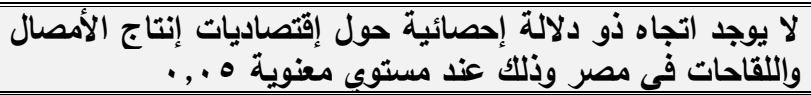 \\
\hline بية & معنوي & $\cdot, \cdots$ & في مصر. تسبب تحرير سعر الصرف فى رفع اسعار الامصال واللقاحات \\
\hline & 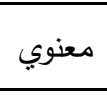 & $\bullet, \cdots$ & في المراكز الصريب سعبة الصرف فى قلة توافر بعض انواع اللقاحات \\
\hline مو & 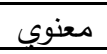 &,$\cdot T V$ & r- اثز تحرير سعر الصرف على العملية التحصينية في مصر . \\
\hline باة & 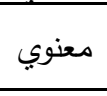 & $\cdot, \cdots$ & التطعيمات والامصدال فعر الصرف سبر سب اساسي فى اختفاء بعض انواع \\
\hline مو & 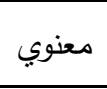 & , , , & العملية التحصينية فحى مصر الصرف من التحديات الرئيسية التى تواجه \\
\hline & 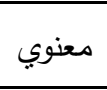 & $\cdot, \cdots$ & 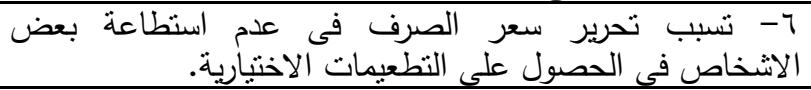 \\
\hline & SEl & $\cdot, \cdots$ & 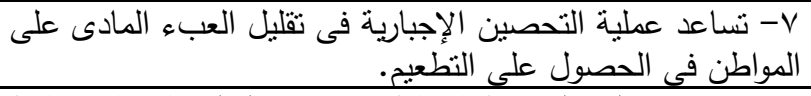 \\
\hline 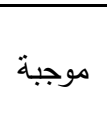 & 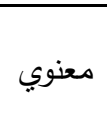 & $\cdot, \cdots$ & 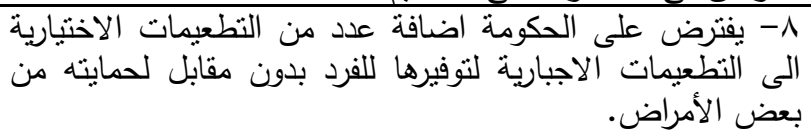 \\
\hline & 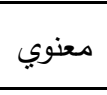 & $\cdot, \cdots$ & 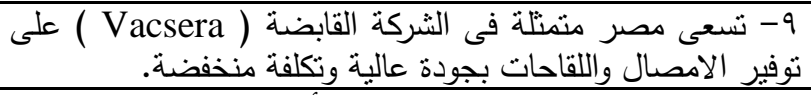 \\
\hline موجبة & معنوي & •, , & اجمالي المحور الأول \\
\hline
\end{tabular}

المصدر: من أعداد الباحثين من مخرجات برنامج SPSS

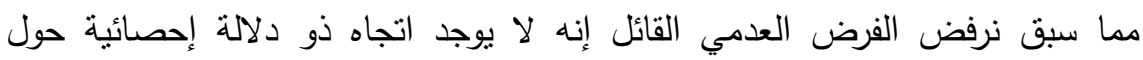
إقتصاديات إنتاج الأمصال واللقاحات في مصر وذللك عند مستوي معنوية ه.,. •، وهو اتجاه ايجابي (بالموافقة كما هو موضح سابقا في مقياس ليكرت) . 
ثانبا: الفرض الثاني: نتائج اختبارات الفروض للمحور الثاني :

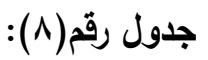

\begin{tabular}{|c|c|c|c|}
\hline الإثشارة & الاتجاه & $\begin{array}{c}\mathbf{P}- \\
\text { value }\end{array}$ & 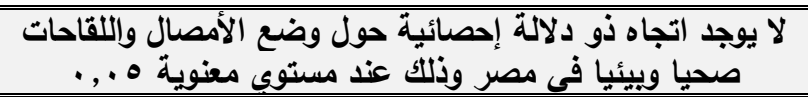 \\
\hline موجبة & معنوي & $\cdot, \cdot$, & العملية التحصنى المجتمع مصر. الدصرى عدد من التحديات التى تواجه \\
\hline 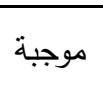 & 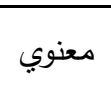 & •, & 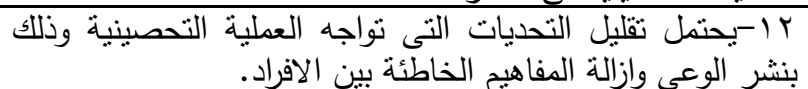 \\
\hline موجبة & 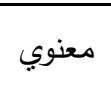 & $\cdot, \cdot \cdot$ & 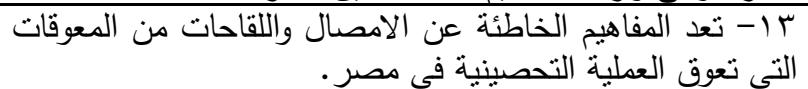 \\
\hline 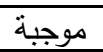 & معنوي & $\cdot, \cdot$, & ع ا- بساعد زيادة الوعى بين الأفراد على إنتثار عملية التحصين. \\
\hline 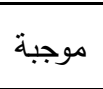 & معنوي & $\cdot, \cdots$ & 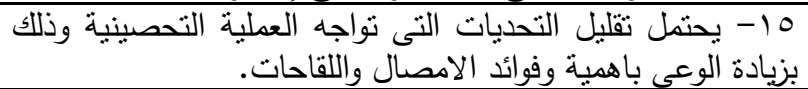 \\
\hline 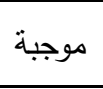 & معنوي & $\cdot, \cdots$ & الافراد. تساعد عملية التحصين فى تقليق إنتشار الأمراض بين \\
\hline 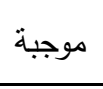 & معنوي & $\bullet \cdot, \cdot$ & الأطفال نتيجة قلة التطعيمات والامصنال. مثرة وفيات الأفراد وخاصة \\
\hline جبة & ي & $\cdot, \cdot$ & الاجبارية. يقل انتشار الأمراض عند زيادة عدد حملات التطعيمات \\
\hline رجبة & معنوي & $\cdot, \cdots$ & 9 عدد الافراد الذين يتم تطعيمهم. الوفيات بين الافراد (وخاصة الاطفال)عند زيادة \\
\hline موجبة - la & 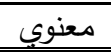 & $\cdot, \cdots$ & اجمالى المحور الثاني \\
\hline
\end{tabular}

المصدر: من أعداد الباحثين من مخرجات برنامج SPSS

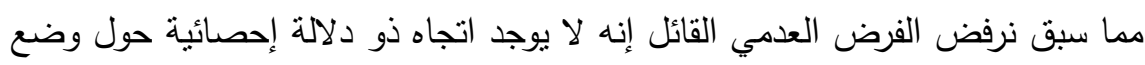

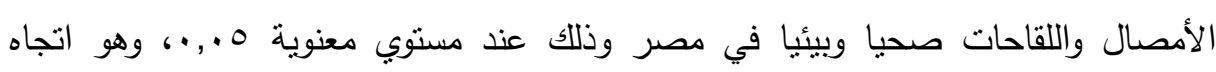

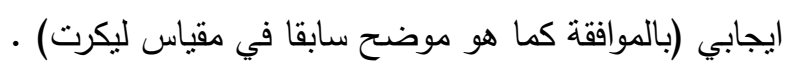

$$
\text { ج- إختبار معنوية الانحدار: }
$$

الفرض الرئيسي: لا يوجد ثاثير ذو دلالة إحصائية لإقتصاديات إنتاج الأمصال واللقاحات

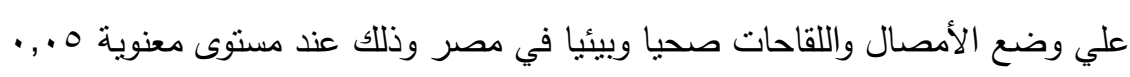


نتائج اختبار الفرض الرئيسي :

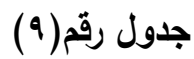

\begin{tabular}{|c|c|c|c|c|}
\hline P-value & إحصاءة F & $\begin{array}{l}\text { معامل التحديد } \\
\text { R2 }\end{array}$ & الانحدار & لا لاقوجداديات إنتاج دلالة إلحصال \\
\hline & $T V \leqslant c$ & • & سזו, & 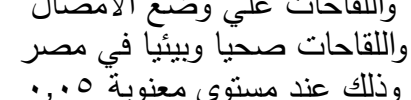 \\
\hline
\end{tabular}

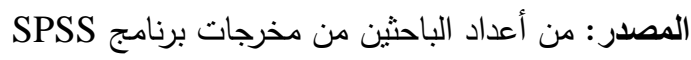

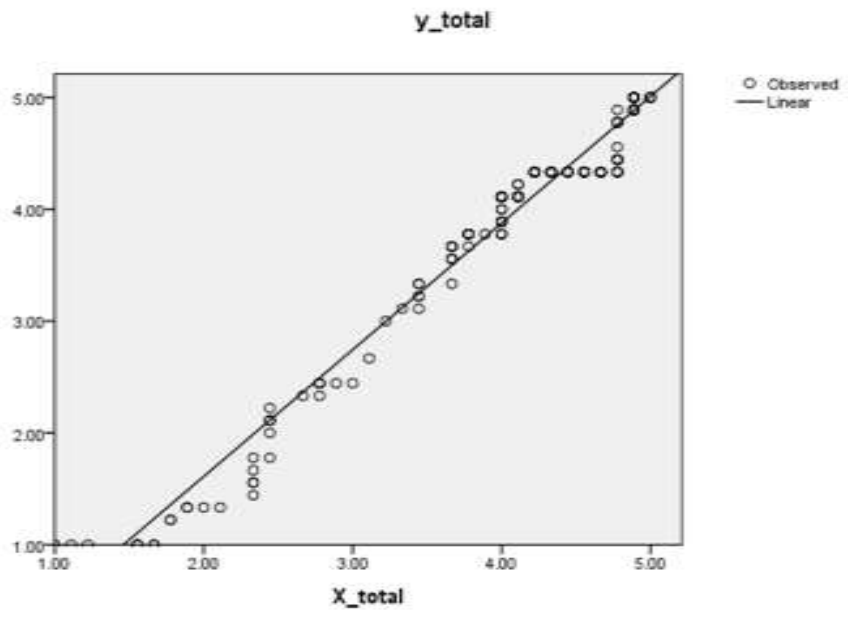

مما سبق نرفض الفرض العدمي القائل إنه لا يوجد تاثير ذو دلالة إحصائية لإقتصاديات

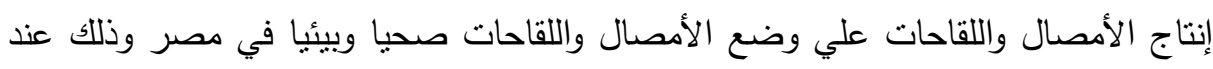

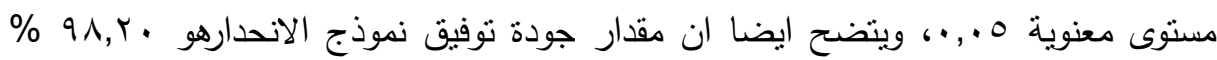
وهي قيمة مرتفعة كما هو موضح في الثكل التالي 
ويمكن كتابة النموذج الرياضي الذي يمنل ناثير إقتصاديات إنتاج الأمصال واللقاحات

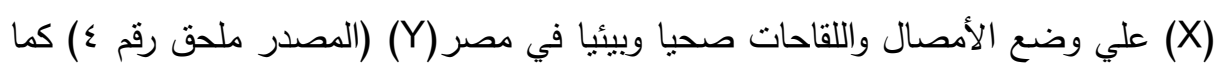

$$
\mathrm{Yi}=-0.656+1.133 \mathrm{Xi}+\mathrm{ei}
$$

ومن النموذج السابق يمكن ملاحظة ان ثابت الانحدار يصف وضع الامصال واللقاحات

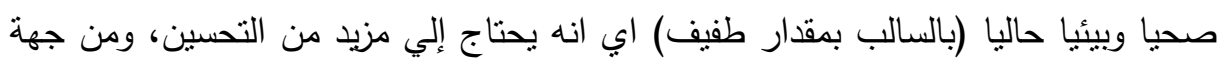

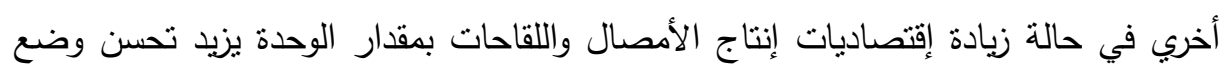

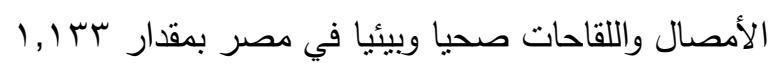

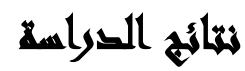

فى ضوء تحليل بيانات الدراسة ودراسة تاثير إقتصاديات إنتاج الأمصال واللقاحات علي وضع الأمصال واللقاحات صحيا وبيئيا في مصر فقد توصلت الدراسة للنتائج التالية . 1-نتاول الباحث من خلال إختبار الفرض الأول القائل أنه لا يوجد اتجاه ذو دلائلة فئل إحصائية

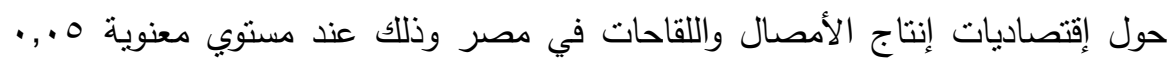
وتمكن الباحث من إثبات انه يوجد اتجاه ذو دلالة إحصائية حول إقتصاديات إنتاج

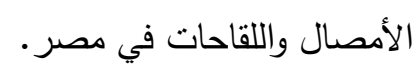
r- تتاول الباحث من خلال إختبار الفرض الثانى القائل أنه لا يوجد اتجاه ذو دلالة إحصائية

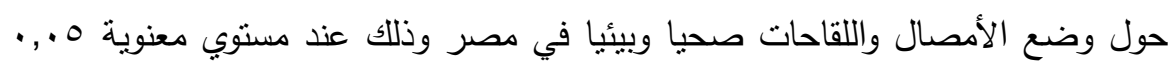

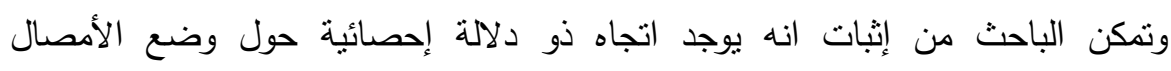
واللقاحات صحيا وبيئيا في مصر . r-تتاول الباحث من خلال إختبار الفرض الرئيسى أنه لا يوجد تاثير ذو دلالة إحصائية

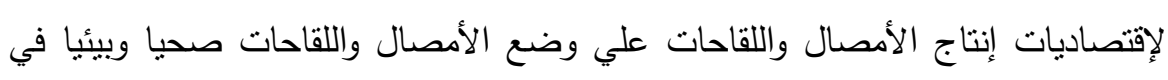
مصر وذللك عند مسنوى معنوية ه ., • وتمكن الباحث من إثبات أنه يوجد ناثير ذو دلالة

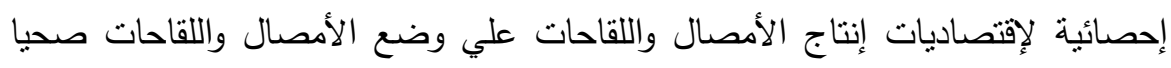
وبيئيا في مصر · 
ع-تختلف الأمصال واللقاحات عن الأدوية باعتبارها منتجات بيولوجية (كائنات حية دقيقة )

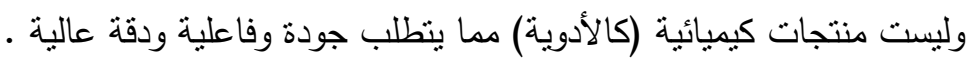

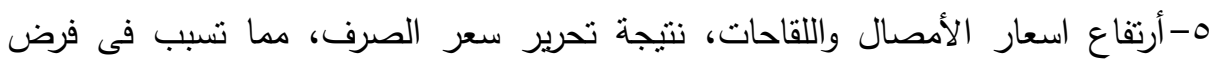

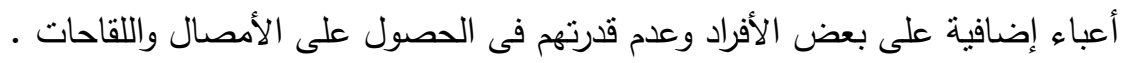

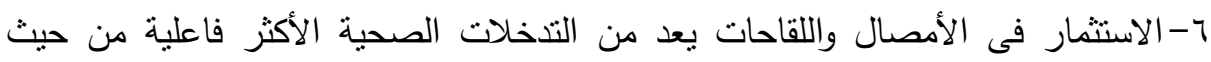
التكلفة حيث يساعد التطعيم فى خفض معدل الإصابات والوفيات وخاصة فى الأطفال بفاعلية وآمان.

\section{تموسيايت التصراسة}

توصل الباحثون الى مجموعة من التوصيات وهى:

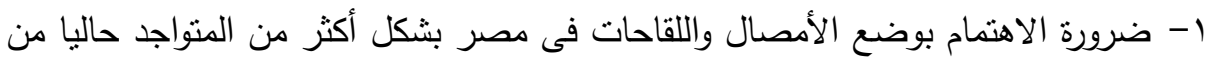

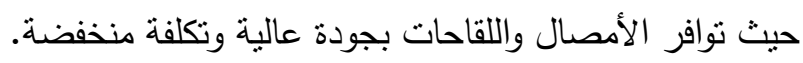
r-ضرورة الاهتمام بتطوير الخدمات الصحية المجانية المقدمة الأفراد.

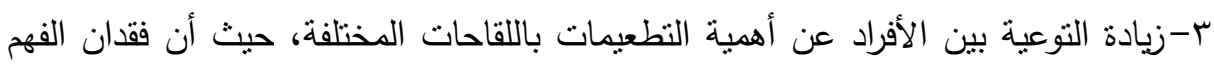
حول أهمية الأمصال واللقاحات ،والمفاهيم الخاطئة لدى بعض الأفراد أحد أهم العوائق

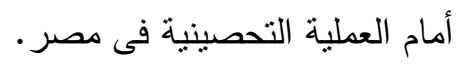
ع-ضرورة زيادة الجهد المبزول من قبل الحكومة، وذلك باضافة بعض التطعيمات الأختبارية الى قائمة التطعيمات الإجبارية لتوفير الحماية للأفراد داخل المجتمع مما يساعد لى تلى تقليل

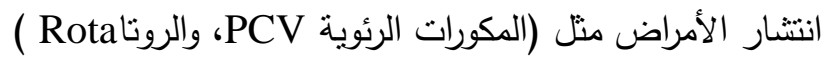

\section{المرالئ}

الزغبى، واخرون(9 . ب): التتمية المستدامة: المفهوم والمكونات ومؤشرات القياس

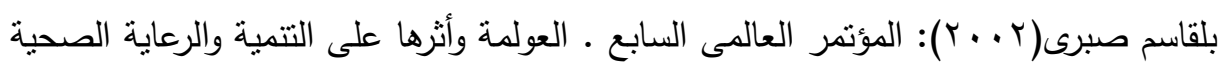

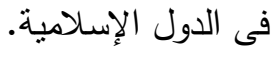




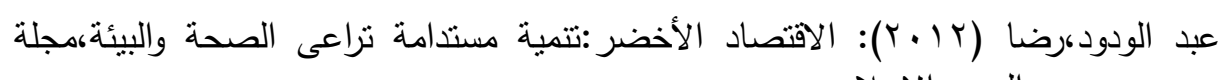

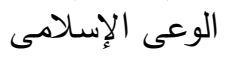

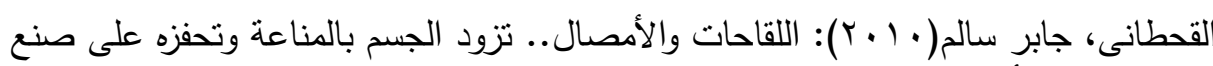
أجسام مضادة تقاوم المرض : ألمات

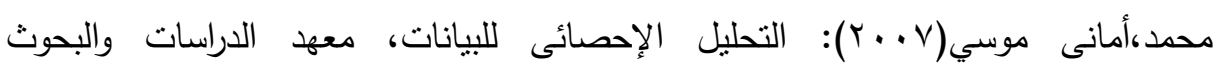
الإحصائية- جامعة القاهرة: الإن

نجم،رباب فتحى (ع ( ب): العولمة ودورها فى توافر اللقاحات والأمصال واتاحتها للدول

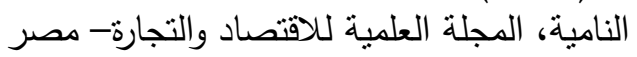

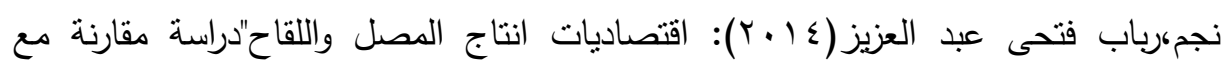
التركيز على الحالة المصرية "، رسالة دكتوراه تجارة عين شمس.

Bahar Ramezanpour 'Cross-Sectoral Perspectives of Market Implementation of the MVA Platform for Influenza Vaccines: Regulatory, Industry and Academia rissue 3 ، Volume7,Issue3

Peng, Yuan, Zheng, DNA Vaccines: The New Directions to Allergic Disease ,J Allergy, (2016): Volume7,Issue2

Venkateswarlu 'Chamcha Current Scenario and Future Prospects of HIV Vaccines ،J AIDS Clin9, 2016 ، Vol 7 ،issue 11 


\title{
A PRACTICAL MODEL TO STUDY THE EFFECT OF THE ECONOMICS OF VACCINE PRODUCTION ON HEALTH AND ENVIRONMENT IN EGYPT
}

Mahmoud S. Abd El-Samee
Mahmoud A. Amin $^{(2)}$; and Heba A. Fanous $^{(2)}$;

1) Post Graduate, Institute of Environmental Studies \& Research, Ain Shams University 2) Faculty of Commerce, Ain Shams University 3) Egyptian Company for Blood Transfusion Services

\begin{abstract}
The aim of this study is to prepare an applied model for the study of the effect of the economics of vaccine production on health and environment in Egypt, which will achieve the greatest benefit for individuals from the availability of serums and vaccines and the ease of immunization process that provides protection For the individuals. Which impede the production of serums, vaccines and immunization in Egypt. These challenges are the presence of some misconceptions and the lack of awareness of some individuals in the community of the benefits of serums, vaccines and the benefits of immunization in reducing diseases and eradicating them in the beginning before they spread and turn into an epidemic. Destroyed The study examined the concept of serums, vaccines and the difference between each of them in order to know the impact of these challenges on the production of vaccines, immunization and immunization process, and the impact of the immunization process in improving the health of individuals and reducing the spread of diseases and reduce the cases of infections. The study was also based on the analytical method in the practical side based on the answers of the sample of the study and on the study data which was obtained through the survey questionnaire which was distributed to the personnel working in the Holding Company for

$$
\text { المجلد السادس والأربعون، الجزء الأول، يونيه } 9 \text {. }
$$


Biologics and Vaccines (275) 261). The valid questionnaire for the analysis is (250) questionnaire. The survey form is the tool used to achieve the objectives of the study by means of the statistical test of the tests using the statistical program SPSS The study found that there is a statistically significant trend in the economics of serums production and vaccines in Egypt at a significant level of 0.05 . There is a statistically significant effect of the production of serums and vaccines on the status of serums and vaccines in health and environment in Egypt at a significant level of 0.05 There is a statistically significant effect for the economics of serums production and vaccines on the status of serums and vaccines in the health and environment in Egypt at a significant level 0.05 